Document downloaded from:

http://hdl.handle.net/10251/144567

This paper must be cited as:

Llopis-Lorente, A.; Villalonga, R.; Marcos Martínez, MD.; Martínez-Máñez, R.; Sancenón Galarza, F. (07-0). A Versatile New Paradigm for the Design of Optical Nanosensors Based on Enzyme-Mediated Detachment of Labeled Reporters: The Example of Urea Detection. Chemistry - A European Journal. 25(14):3575-3581.

https://doi.org/10.1002/chem.201804706

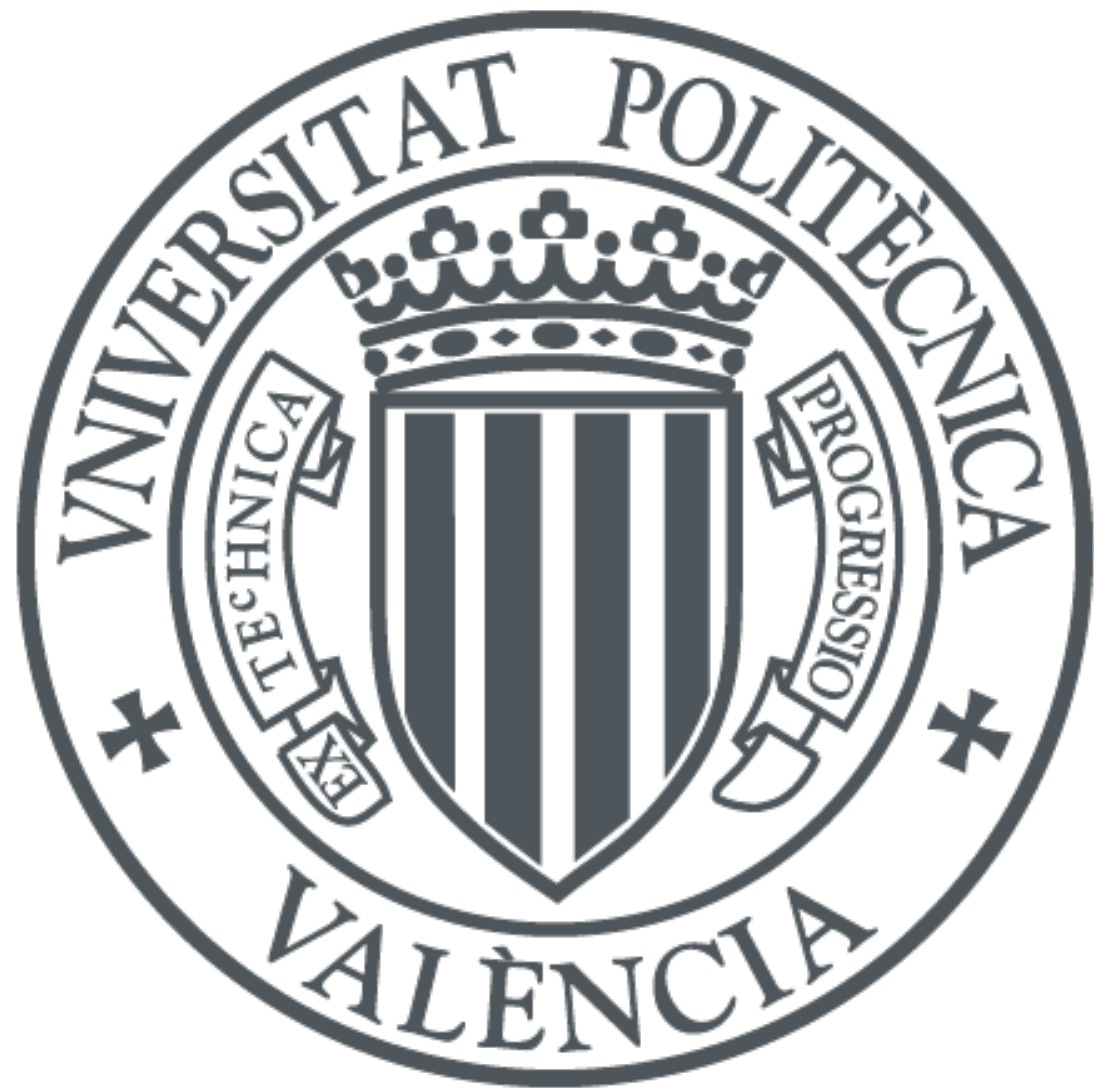

The final publication is available at

https://doi.org/10.1002/chem.201804706

Copyright John Wiley \& Sons

Additional Information

"This is the peer reviewed version of the following article: Llopis-Lorente, Antoni, Reynaldo Villalonga, M. Dolores Marcos, Ramón Martínez-Máñez, and Félix Sancenón. 2018. A Versatile New Paradigm for the Design of Optical Nanosensors Based on Enzyme\&\#8208;Mediated Detachment of Labeled Reporters: The Example of Urea Detection. Chemistry A European Journal 25 (14). Wiley: 357581. doi:10.1002/chem.201804706. , which has been published in final form at https://doi.org/10.1002/chem.201804706. This article may be used for non-commercial 


\title{
Versatile new paradigm for the design of optical nanosensors based on enzyme-mediated detachment of labelled-reporters: The example of urea detection
}

\author{
Antoni Llopis-Lorente, ${ }^{[a, b, c]}$ Reynaldo Villalonga, ${ }^{[\mathrm{d}]}$ M. Dolores Marcos, ${ }^{[\mathrm{a}, \mathrm{b}, \mathrm{c}, \mathrm{e}, \mathrm{f}]}$ Ramón Martínez- \\ Máñez ${ }^{\star[a, b, c, e, f]}$ and Félix Sancenón ${ }^{[a, b, c, e, f]}$
}

\begin{abstract}
Here we present a novel bio-inspired nanoarchitectonics approach for the design of optical probes. It is based on nanodevices that combine (i) an enzymatic receptor subunit, (ii) a signalling subunit (consisting of a labelled-reporter attached to a silica surface), and (iii) a mechanism of communication between the two sites founded on the production of chemical messengers by the enzymatic subunit that induces the detachment of the reporter molecules from the silica surface. As a proof of concept, a urea nanosensor based on the release of Alexa Fluor 647-labelled oligonucleotide from enzyme-functionalized Janus Au-MSNPs (goldmesoporous silica nanoparticles) has been developed. Janus AuMSNPs are functionalized on the silica face with amino groups to which the labelled oligonucleotide is attached by electrostatic interactions, whereas the gold face is used for grafting the urease enzyme. The nanodevice is able to release fluorescentoligonucleotide via enzyme-mediated hydrolysis of urea to ammonia and the subsequent deprotonation of amino groups on the silica face. This simple nanodevice has been applied for the flurorimetric detection of urea in real human blood samples and for the identification of adulterated milk. Given the large variety of enzymes and reporter species that could be combined, we believe this is a general new paradigm that could applied to the design of a number
\end{abstract}

[a] A. Llopis-Lorente, Dr. M. D. Marcos, Prof. R. Martínez-Máñez, Dr. F. Sancenón.

Instituto de Reconocimiento Molecular y Desarrollo Tecnológico (IDM), Universitat Politècnica de València, Universitat de València, Spain

[b] A. Llopis-Lorente, Dr. M. D. Marcos, Prof. R. Martínez-Máñez, Dr. F. Sancenón.

Departamento de Química, Universitat Politècnica de València. Camino de Vera s/n, 46022, Valencia, Spain.

E-mail: rmaez@qim.upv.es

[c] A. Llopis-Lorente, Dr. M. D. Marcos, Prof. R. Martínez-Máñez, Dr. F. Sancenón.

CIBER de Bioingeniería, Biomateriales y Nanomedicina (CIBERBBN) (Spain)

[d] Dr. R. Villalonga.

Department of Analytical Chemistry, Faculty of Chemistry, Complutense University of Madrid, 28040 Madrid (Spain)

E-mail: rvillalonga@quim.ucm.es

[e] Dr. M. D. Marcos, Prof. R. Martínez-Máñez, Dr. F. Sancenón. Unidad Mixta de Investigación en Nanomedicina y Sensores. Universitat Politècnica de València, Instituto de Investigación Sanitaria La Fe, Valencia, Spain.

[f] Dr. M. D. Marcos, Prof. R. Martínez-Máñez, Dr. F. Sancenón Unidad Mixta UPV-CIPF de Investigación en Mecanismos de Enfermedades y Nanomedicina, Valencia, Universitat Politècnica de València, Centro de Investigación Príncipe Felipe, Valencia, Spain.

Supporting information for this article is given via a link at the end of the document. of optical probes for the detection of target analytes.

\section{Introduction}

The chromo-fluorogenic detection of analytes (cations, anions and neutral molecules) of biomedical and environmental interest is a primary research topic due to their potential applications in different fields. ${ }^{[1]}$ Chromo-fluorogenic probes (also called chemosensors) offer certain advantages such as no need to use sophisticated equipment or highly-trained personnel, low cost, rapid response and in-situ detection. ${ }^{[2]}$ Most chemosensors are usually molecular entities that incorporate (i) a receptor subunit (that interacts with analyte), (ii) a signalling subunit (usually a fluoro-chromophore group) and (iii) a mechanism of communication between the two subunits (e.g. photinduced electron transfer (PET), electronic energy transfer (EET), etc.) (Figure 1a). ${ }^{[3]}$ A key step when designing an optical probe is to find the receptor group that interacts specifically with the target analyte.

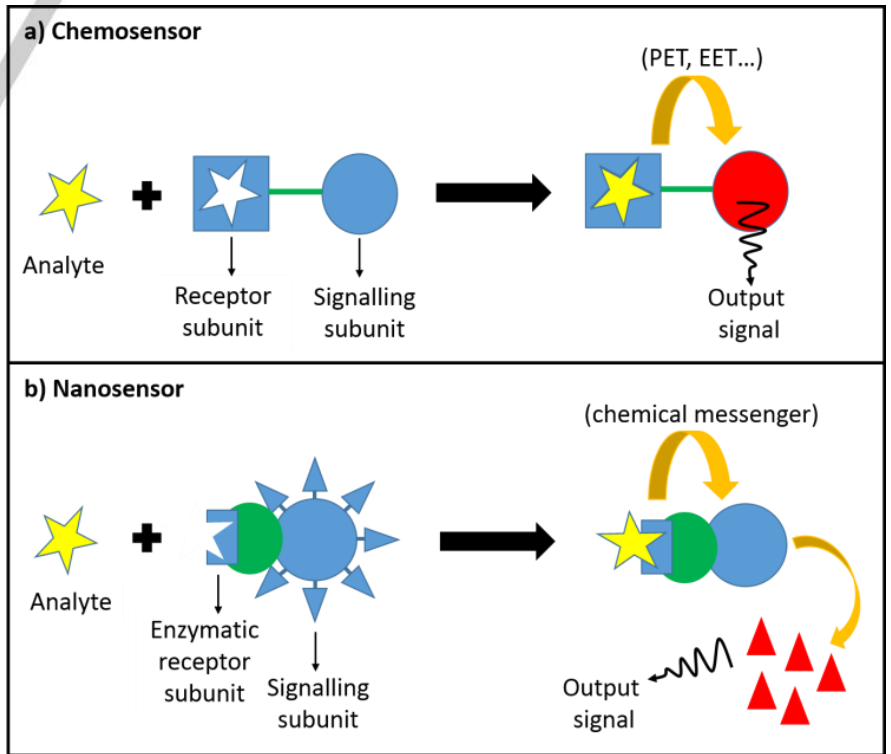

Figure 1. a) Schematic of a typical chromo-fluorogenic probe containing a receptor subunit and a signalling subunit. b) Schematic of the bio-inspired nanoarchitectonics approach proposed in this paper for the design of nanosensors combining an enzymatic receptor subunit and a hybrid signalling subunit. 
When talking about chromo-fluorogenic chemosensors, the design of probes for small neutral biomolecules is challenging due to their lower reactivity compared to cations and anions. In natural systems, recognition of small biomolecules is accomplished by antibodies, enzymes and other bioreceptors. ${ }^{[4]}$ Whereas antibodies bind to the target molecule, enzymes transform their specific substrates into new chemicals. On the other hand, nanoarchitectonics has been regarded as a promising approach to develop advanced nanoscale materials based on the synergic combination of different nano-(bio)components using nanotechnology, supramolecular and molecular chemistry, and bio-related technologies. ${ }^{[5]}$ Inspired by both traditional chemosensors and the role of enzymes in living systems, we envisioned a new versatile paradigm for the design of optical probes based on hybrid nanodevices incorporating (i) enzymes as receptor subunit, (ii) fluoro-chromogenic species linked to a silica surface as the signalling subunit and (iii) a mechanism of communication between the two subunits based on the production of "chemical messengers" by the enzymes that induce the detachment and release of the fluorochromophore. As proof of concept, we present here a urea nanosensor based on Janus Au-MSNPs (gold-mesoporous silica nanoparticles) functionalized with Alexa Fluor 647-labelled oligonucleotide on the silica surface and with urease on the gold surface (Figure 2).

In the scientific literature, the term Janus is used to define particles that have two (or more) surfaces with different chemical and physical properties. ${ }^{[6]}$ Janus particles with different morphologies and 3D architectures have been designed such as half-and-half hemispheres, rods, dumbbell-, acorn- or (like in the present study) snowman-shaped particles. ${ }^{[7]}$ Besides, the integration of metal nanoparticles and silica materials in Janus or core-shell structures for detection applications has been reported in several studies. ${ }^{[8]}$

Urea $\left[\left(\mathrm{NH}_{2}\right)_{2} \mathrm{CO}\right]$ is a key molecule in human, animal and plant metabolism. It is a major component of blood plasma and urine and its determination is of considerable interest in clinical and agricultural settings. ${ }^{[9]}$ In humans, urea is synthesized in the livers for the removal of ammonia generated from the breakdown of proteins and amino acids. From the liver, urea is transported by the blood to the kidneys and finally excreted in urine. In plasma, urea normal levels are from $2.5 \mathrm{mM}$ to $7.5 \mathrm{mM}$ and concentrations above this range can be indicative of renal dysfunctions, liver disease or dietetic problems. ${ }^{[10]}$ On the other hand, urea has been identified amongst the most common chemicals used in milk adulteration, especially in developing countries. ${ }^{[11]}$ It is added with the aim of increasing the solid nonfat content determined by conventional tests and consumption of milk adulterated with urea can cause serious health problems. Furthermore, urea levels in cattle milk are a useful parameter to control animal health, and levels above $40 \mathrm{mg} \cdot \mathrm{dL}^{-1}(6.6 \mathrm{mM})$ can be indicative of disease. ${ }^{[12]}$ In the last 3 years, the development of simple methodologies for urea detection has attracted considerable attention and several studies have been reported (see Table SI-1), ${ }^{[13]}$ most of them based on electrochemical sensing. ${ }^{[13 a-j]}$ Whereas previous electrochemical sensors have generally required two enzymes (urease and glutamate dehydrogenase) and mediators (e.g., NADH, L-glutamate, ferrocene) to complete electron transfer to the electrode ${ }^{[14]}$ recent studies aim to reduce complexity and the number of chemicals needed by using polymer composites and graphene modified electrodes. ${ }^{[13 a-j]}$ Furthermore, a colorimetric method based on the aggregation of unmodified gold nanoparticles with a detection limit of $20 \mathrm{mM},{ }^{[13 \mathrm{k}]}$ and a urea probe based on the

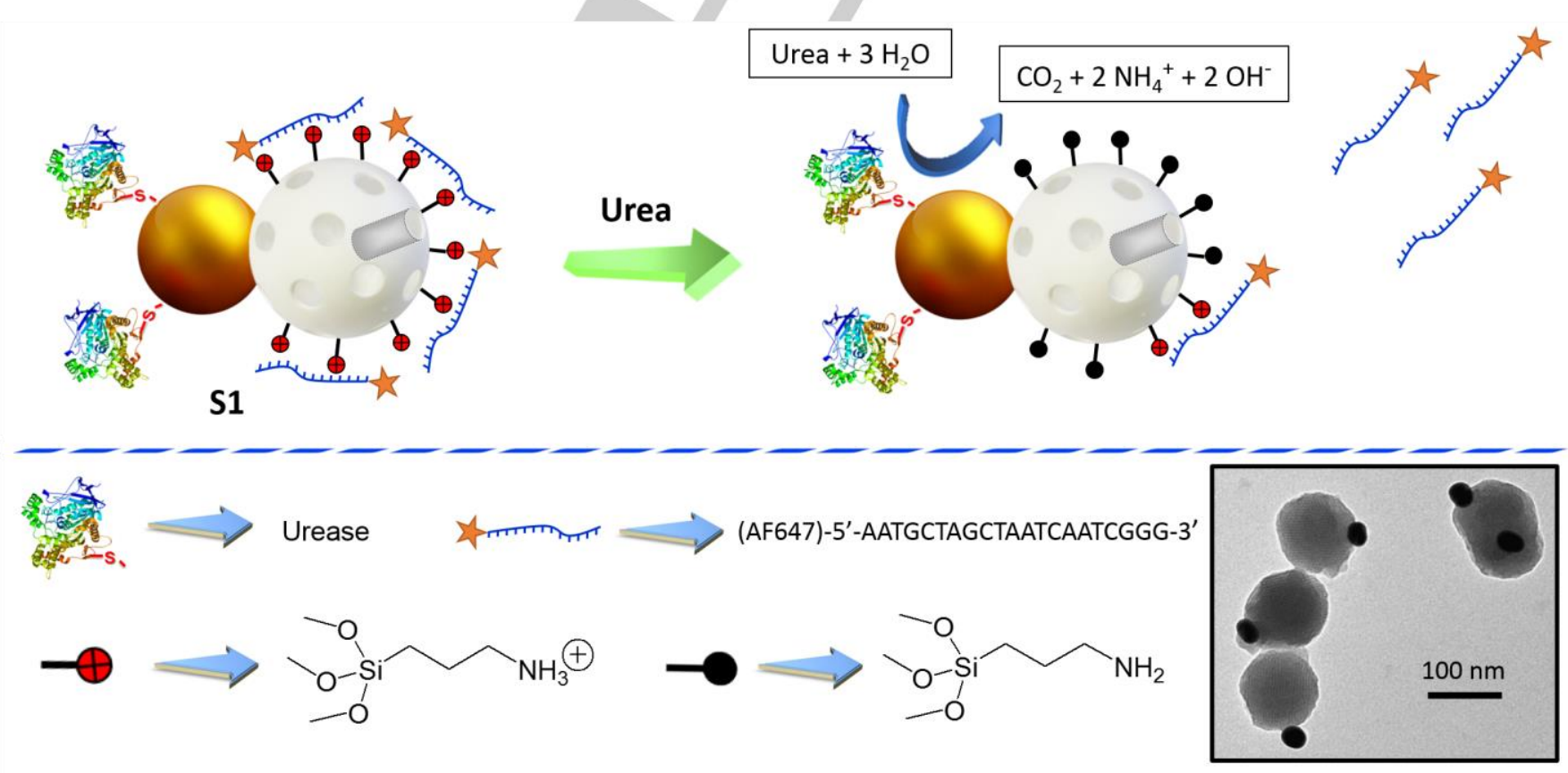

Figure 2. Representation of the design and sensing performance of the nanosensor S1. Inset: TEM image of Janus Au-MSNPs. 
magnetization of iron nanoparticles in oil-in-water emulsions have been reported. ${ }^{[13]}$ Despite these advances, the development of simple methods for urea sensing in complex matrices (i.e. plasma, milk) to reduce analysis time and avoid the use of sophisticated equipment remains a topic of interest.

\section{Results and Discussion}

The design and sensing paradigm of the urea nanosensor (S1) based on the release of labelled-oligonucleotide from Janus-type Au-mesoporous silica nanoparticles mediated by an integrated enzymatic unit (urease) are depicted in Figure 2. The silica face, in the Janus nanoparticles, is functionalized with amino moieties (positively charge at neutral $\mathrm{pH}$ ) to which oligonucleotides attach via electrostatic interactions. ${ }^{[15]}$ The oligonucleotide strand contains 20 nucleotides and is labelled with a fluorescent dye (Alexa Fluor 647) on its 5'-end. Moreover, the gold face is used for immobilizing urease enzyme. The nanosensor produces a strong fluorescent signal in the presence of urea as a consequence of its recognition by the enzyme and transformation into ammonia and $\mathrm{CO}_{2}$. This induces a local decrease of the $\mathrm{pH}$ and deprotonation of the amino moieties on the silica face which results in the release of the labelled-oligonucleotide to the solution.

In order to prepare the nanosensor, firstly, mesoporous silica nanoparticles (MSNPs) were synthesized by condensation of tetraethyl orthosilicate in alkaline media using $n$ cetyltrimethylammonium bromide (CTAB) micelles as a template. Gold nanoparticles (AuNPs) were synthesized by reduction of $\mathrm{Au}$ (III) with sodium citrate. Next, MSNPs were partially functionalized with (3-mercaptopropyl)trimethoxysilane by confinement at the interface of an emulsion between paraffin wax and an aqueous phase, and AuNPs were then attached to MSNPs by the formation of Au-S bonds with thiols on the silica surface. The paraffin wax was removed by washing the nanoparticles with $\mathrm{CHCl}_{3}$, which yielded the Janus Aumesoporous silica nanoparticles (Au-MSNPs). ${ }^{[16]}$ Then, the gold face was functionalized by treatment with 3-mercaptopropionic acid and afterward the silica surface was functionalized with amino moieties by treatment with an excess of (3aminopropyl)triethoxysilane. The resulting solid (SO) was stirred in a solution of a labelled oligonucleotide ((Alexa Fluor 647)-5'AATGCTAGCTAATCAATCGGG-3') in phosphate buffer at $\mathrm{pH}$ 7.5 for $30 \mathrm{~min}$, washed, and further functionalized with urease by coupling the enzyme with carboxylic groups on the gold face via the use of ethyl(dimethylaminopropyl)carbodiimide (EDC) and $\mathrm{N}$ hydroxysuccinimide (NHS). This process finally yielded the sensing nanodevice S1 (Figure 1), which was kept in the refrigerator in phosphate buffer solutions $(\mathrm{pH} 7.5)$ until use.

The prepared materials were characterized using standard procedures (see Supporting Information). TEM images (inset in Figure 1 and Figure SI-1) confirmed the linkage between MSNPs nanoparticles (ca. 80-100 nm) and AuNPs (ca. $20 \mathrm{~nm}$ ) yielding the Janus-type Au-MS structure. Absorption spectra showed the characteristic gold surface plasmon resonance at $525 \mathrm{~nm}$ for AuNPs, with a red-shift to $532 \mathrm{~nm}$ for Au-MSNPs due to the increase in the refractive index around the gold surface induced by the coupling with the mesoporous silica (Figure SI-2). Additionally, low-angle powder X-ray diffraction (PXRD) patterns (Figure SI-3) of the MSNPs and Au-MSNPs showed the (100) reflection peak that is characteristic of mesoporous silica materials. At high angles, the PXRD pattern of the Au-MSNPs Janus colloids showed the cubic gold (111), (200), (220), and (311) peaks which confirmed the presence of gold nanocrystals observed by TEM. Conservation of low- and high-angles peaks in $\mathbf{S O}$ confirmed that the functionalization processes did not damage the 3D structure. The total surface area of starting MSNPs was $1299.86 \mathrm{~m}^{2} \cdot \mathrm{g}^{-1}$, determined from $\mathrm{N}_{2}$ adsorption-desorption isotherms, and reduced to $974.28 \mathrm{~m}^{2} \cdot \mathrm{g}^{-1}$ for Au-MSNPs due to the incorporation of non-porous gold nanoparticles (Figure SI-4). The zeta potential of the MSNPs and Au-MSNPs was -39.9 and $-39.4 \mathrm{mV}$ (at pH 7.5) respectively and for So the total charge was reduced $(-16 \mathrm{mV})$ due the functionalization of the silica face with aminopropyl groups. For the final nanodevice $\mathbf{S 1}$, the negative charge increased to -30 $\mathrm{mV}$ due to the attachment of oligonucleotide strands on the silica face and to the immobilization of urease on the gold surface. From dynamic light scattering measurements, the hydrodynamic diameter for the sensing nanoparticles $\mathbf{S} \mathbf{1}$ was determined to be $111 \pm 20 \mathrm{~nm}$ (Figure SI-5). From elemental analysis of S0, the amount of anchored aminopropyl moieties was determined to be $1.6 \mathrm{mmol}$ per gram of solid. The amount of labelledoligonucleotide on the final nanodevice $\mathbf{S 1}$ was $2 \mu \mathrm{mol}$ per gram of solid, as determined by fluorescence. The activity of immobilized urease on $\mathbf{S 1}$ was $820 \mathrm{U} \cdot \mathrm{g}^{-1}$, as determined using a standard assay (see Experimental Section and Figure SI-6), which corresponds to $12.7 \mathrm{mg}$ of commercial enzyme per $\mathrm{g}$ of s1.

To assess the feasibility of the proposed nanosensor, we first monitored the release of labelled-oligonucleotide from $\mathbf{S} 1$ in aqueous media in the absence and presence of urea. For these experiments, $\mathbf{S} 1$ aliquots were brought to a concentration of 0.3 $\mathrm{mg} \cdot \mathrm{mL}^{-1}$ in phosphate buffer solution (PBS, $\mathrm{pH}$ 7.5) containing either 0 or $5 \mathrm{mM}$ of urea and stirred at room temperature $\left(25^{\circ} \mathrm{C}\right)$. At scheduled times, aliquots were taken, centrifuged to remove the nanoparticles and the release of labelled-oligonucleotide to the solution was evaluated by measuring the emission band of Alexa Fluor 647 at $664 \mathrm{~nm}\left(\lambda_{\mathrm{exc}}=649 \mathrm{~nm}\right)$. The oligonucleotide release kinetics are displayed in Figure 2. As can be seen, in the absence of urea, the fluorescence emission was negligible since amino moieties on the silica surface are protonated $\left(p k_{a}=9.6\right)^{[17]}$ and the oligonucleotide remains attached by the formation of electrostatic interactions. ${ }^{[18]}$ In contrast, in the presence of urea a strong fluorescence signal was observed due to the release of labelled-oligonucleotide from $\mathbf{S} 1$ to the solution. This emission enhancement was ascribed to the recognition of urea by the enzymatic unit on $\mathbf{S 1}$, which catalysed the formation of carbon dioxide and ammonia. In turn, ammonia induced the deprotonation of amino moieties on $\mathbf{S 1}$, which broke the electrostatic interactions with phosphate groups and produced the release of labelled-oligonucleotide. Besides, an increase in the $\mathrm{pH}$ of the media was observed as a result of ammonia formation. In order to confirm the sensing mechanism, we 
checked that the fluorescence of (Alexa Fluor 647)-labelled oligonucleotide alone was not affected by the $\mathrm{pH}$ of the media or the presence of urea. In addition, urea did not induce any increase in fluorescence when Janus nanoparticles containing the labelled-oligonucleotide but without urease enzyme were used.

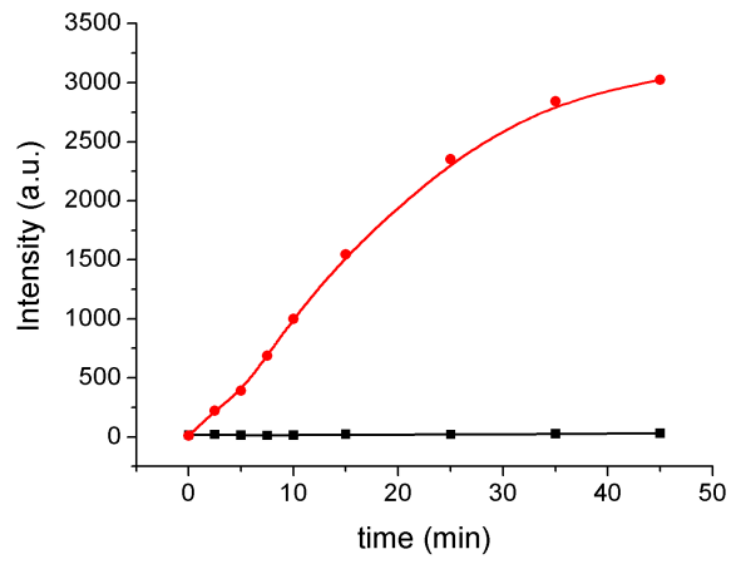

Figure 3. Labelled-oligonucleotide release from $\mathbf{S 1}$ determined by measuring emission at $664 \mathrm{~nm}\left(\lambda_{\mathrm{exc}}=649 \mathrm{~nm}\right)$ in water solutions (PBS, pH 7.5) in the absence (black curve) and in the presence (red curve) of urea ( $5 \mathrm{mM})$.

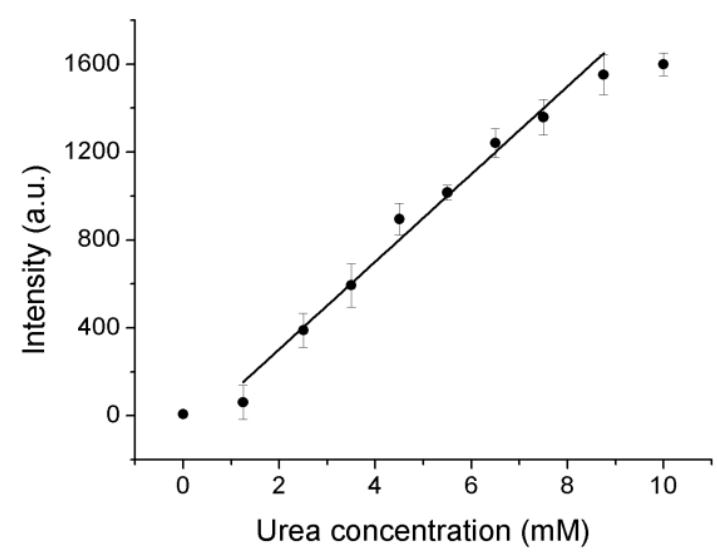

Figure 4. Emission at $664 \mathrm{~nm}\left(\lambda_{\mathrm{exc}}=649 \mathrm{~nm}\right)$ associated with the release of labelled-oligonucleotide release from $\mathbf{S 1}$ as a function of urea concentration in water solutions (PBS, pH 7.5) after $10 \mathrm{~min}$ of incubation.

In a next step, we studied the response of the nanosensor S1 as a function of urea concentration. S1 nanoparticles were suspended in PBS $\left(0.3 \mathrm{mg} \cdot \mathrm{mL}^{-1}, \mathrm{pH}\right.$ 7.5) with different concentrations of urea, incubated for $10 \mathrm{~min}$ and afterward the fluorescence of the released labelled-oligonucleotide was measured. As can be seen in Figure 4, a gradual enhancement in fluorescence was observed upon increasing the amount of urea. Particularly, a linear increase occurred in the range 1.25-
$8.75 \mathrm{mM}$ and a limit of detection of $0.5 \mathrm{mM}$ was calculated from the calibration curve. In terms of clinical applications, the linear range of nanosensor $\mathbf{S} \mathbf{1}$ confers it a competitive basis to monitor urea within the normal clinical range found in blood plasma (2.5$7.5 \mathrm{mM}$ ). Additionally, the nanosensor $\mathbf{S 1}$ may also be employed for the analysis of higher urea concentrations, such as that found in plasma of patients with renal problems or the normal concentrations in urine $(700-130 \mathrm{mM}),{ }^{[19]}$ by simply performing dilutions of the samples.

In a further step, we confirmed the selectivity of the sensing nanodevice by evaluating the response of $\mathbf{S 1}$ in the presence of other biomolecules such as glucose, creatinine and uric acid at physiological concentrations. For these experiments, S1 $\left(0.3 \mathrm{mg} \cdot \mathrm{mL}^{-1}\right)$ was suspended in aqueous solutions at $\mathrm{pH} 7.5$ (PBS) in the presence of each chemical and incubated for 10 minutes. Then, the fluorescence of the released labelledoligonucleotide was determined. As can be seen in Figure 5 , these biomolecules did not produce any appreciable increase in fluorescence which indicated that the oligonucleotide remained attached to $\mathbf{S 1}$. In an additional experiment, the response of $\mathbf{S} 1$ was tested in a solution containing a mixture of these potential interferences and urea, and a clear fluorescent signal was observed indicating the selective recognition of urea with the subsequent release of oligonucleotide in this complex mixture.

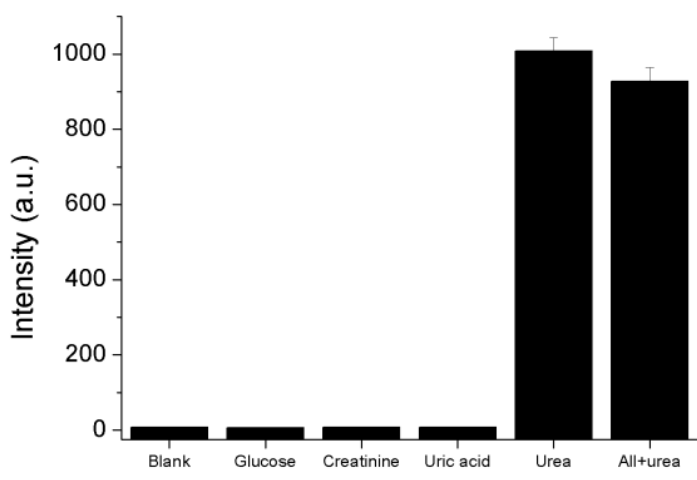

Figure 5. Emission at $664 \mathrm{~nm}\left(\lambda_{\mathrm{exc}}=649 \mathrm{~nm}\right)$ associated with the labelled oligonucleotide release from $\mathbf{S} 1$ in the presence of different biomolecules at physiological concentrations (glucose $(5 \mathrm{mM})$, creatinine $(80 \mu \mathrm{M})$, uric acid $(0.3 \mathrm{mM}))$, in the presence of urea $(5 \mathrm{mM})$ and in a mixture of these potential interferents and urea $(5 \mathrm{mM})$.

Encouraged by the above mentioned results, we decided to evaluate the potential use of nanosensor $\mathbf{S 1}$ for the detection of urea in real human blood samples. Blood samples were obtained from a healthy volunteer, and were centrifuged to separate the plasma (see Experimental Section and Figure SI-7 for details). In order to perform the analysis, $15 \mu \mathrm{L}$ of plasma samples spiked with different amounts of urea were added over $135 \mu \mathrm{L}$ of a $\mathbf{S} 1$ suspension $\left(0.3 \mathrm{mg} \cdot \mathrm{mL}^{-1}\right)$ and incubated for 10 minutes. After this, aliquots were centrifuged to eliminate the nanoparticles and the fluorescence of the supernatant was then 
measured. Remarkably, as can be seen in Figure 6, a significant and proportional increase in fluorescence was observed as a function of the urea concentration in plasma. The analysed range was selected taking into account that in patients with renal dysfunctions urea concentration in blood is in the $20-50 \mathrm{mM}$ range and that it decreases to less than $10 \mathrm{mM}$ after dialysis. ${ }^{[20]}$ The obtained response clearly indicated that plasma samples with abnormal levels of urea can be analysed by adding small amounts of the sample $(15 \mu \mathrm{L})$ over a suspension containing $\mathbf{S 1}$. Additionally, from the intercept of the resulting calibration line $(y=60.93+17.54 x)$ with the $x$-axis, a urea concentration of 3.5 $\mathrm{mM}$ in the original (non-spiked) blood was determined, which is a normal value for a healthy person. Furthermore, we used this calibration to estimate the concentration of two samples spiked with urea (with a final concentration of $23.5 \mathrm{mM}$ and $43.5 \mathrm{mM}$ respectively). Using the procedure described above, urea concentration was determined to be 26.4 and $42.6 \mathrm{mM}$ respectively, with recovery ratios of 112 and $98 \%$, respectively.

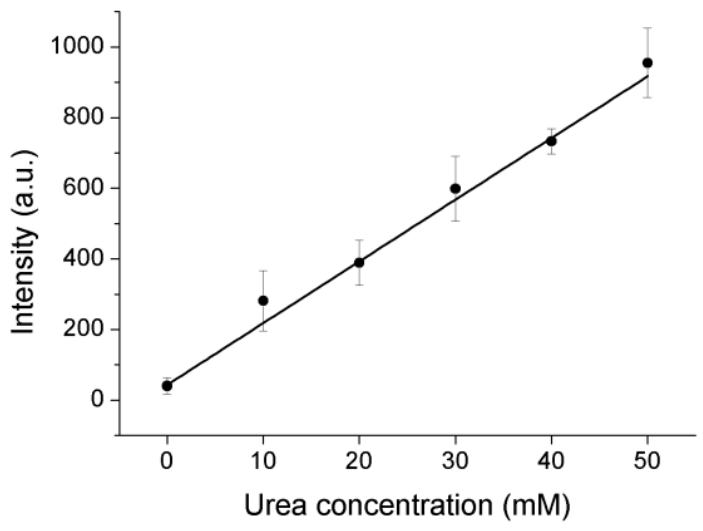

Figure 6. Emission at $664 \mathrm{~nm}\left(\lambda_{\mathrm{exc}}=649 \mathrm{~nm}\right)$ as a function of spiked urea concentration in human blood plasma associated with the release of labelledoligonucleotide from $\mathbf{S 1}$ after $10 \mathrm{~min}$ of incubation.

Finally, we tested the potential use of $\mathbf{S} 1$ to detect urea in adulterated milk. For these experiments, we used commercial milk that had been either spiked or not with urea $(20 \mathrm{mM})$. In a similar way to the experiments performed in human blood, $15 \mu \mathrm{L}$ of milk (previously centrifuged using centrifugal filters to remove turbidity) were added over aqueous solutions of $\mathbf{S 1}\left(0.3 \mathrm{mg} \cdot \mathrm{mL}^{-}\right.$ $\left.{ }^{1}\right)$ and stirred for 10 minutes at room temperature. As can be seen in Figure 7, a remarkable difference in the supernatant fluorescence was observed between adulterated and nonadulterated milk samples. This fact points out the ability of $\mathbf{S} \mathbf{1}$ to identify abnormal urea levels in milk (indicative of adulteration).

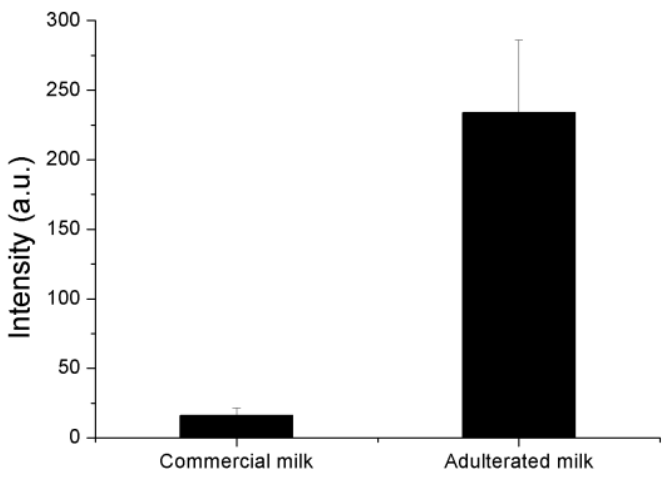

Figure 7. Discrimination between adulterated (containing $20 \mathrm{mM}$ of urea) and non-adulterated milk using S1. Emission at $664 \mathrm{~nm}\left(\lambda_{\mathrm{exc}}=649 \mathrm{~nm}\right)$ associated with the release of labelled-oligonucleotide release from $\mathbf{S 1}$ after $10 \mathrm{~min}$ of incubation with adulterated and non-adulterated milk.

\section{Conclusions}

In summary, we report here a new nanoarchitectonicsbased approach for the design of optical probes that combine (i) an enzymatic receptor subunit, (ii) a hybrid signalling subunit (consisting of labelled-reporter molecules attached to a silica surface by labile interactions), and (iii) a mechanism of communication between the two sites founded on the production of chemical messengers by the enzymatic subunit that induces the detachment of reporter molecules from the silica surface. As a proof-of-concept, the design, preparation and characterization of a nanodevice for urea detection based on the release of fluorescent-oligonucleotide from enzyme-functionalized Janus Au-mesoporous silica nanoparticles has been presented. The nanosensor consists of Janus-type Au-mesoporous silica nanoparticles functionalized with a fluorescent-oligonucleotide (on the silica face via electrostatic interactions with previously anchored 3-aminopropyl moieties) and with urease (by coupling the enzyme with carboxylic groups on the gold face). The sensing mechanism is based on the recognition of urea by the enzymatic unit and the production of ammonia (chemical messenger), which induces the detachment of the fluorescent oligonucleotide strand from the silica surface. The nanosensor was able to detect the presence of urea and a linear response was observed in the 1.25-8.75 mM concentration range, which covers the normal clinical range in plasma (from $2.5 \mathrm{mM}$ to 7.5 $\mathrm{mM}$ ). We demonstrated the applicability of the nanosensor for the detection of urea in human blood samples and for the identification of adulterated milk. Regarding the sensing of urea, this fluorescent nanosensor represents a simple and novel alternative to previously reported electrochemical and optical sensors and allows urea detection in real samples. Notwithstanding, given the knowledge acquired in the field of chemosensors and supramolecular chemistry in the design of labile linkages that can be broken by common enzymatic products (e.g. $\mathrm{H}_{3} \mathrm{O}^{+}, \mathrm{OH}^{-}, \mathrm{H}_{2} \mathrm{O}_{2}$, nucleophiles, etc.), this 
approach could open new directions towards the development of novel optical sensors. Furthermore, mesoporous silica offers the additional possibility of loading an additional cargo (dye or fluorophore) in the inner of the pores and will allow the development multisignalling nanosensors that combine the detachment of labelled-reporters from the external surface with the release of cargos from the pores. From a broad perspective, we believe that these results could inspire the development of nanodevices based on the combination of enzymatic effectors and the detachment of different reporter species for the design of easy-to-use detection kits of analytes of biomedical and environmental interest.

\section{Experimental Section}

Chemicals. Tetraethyl orthosilicate (TEOS), n-cetyltrimethylammonium bromide (CTABr), sodium hydroxide $(\mathrm{NaOH})$, (3mercaptopropyl)trimethoxysilane, hydrogen tetrachloroaurate(III) $\left(\mathrm{HAuCl}_{4} \cdot 3 \mathrm{H}_{2} \mathrm{O}\right)$, sodium citrate tribasic dihydrate, paraffin wax, 3mercaptopropionic acid, urease from Jack Beans (type IX), (3aminopropyl)triethoxysilane, $\quad \mathrm{N}$-hydroxysuccinimide $\quad$ (NHS), $\mathrm{N}$-(3dimethylaminopropyl)- $N$-ethylcarbodiimide hydrochloride (EDC), urea, glucose, creatinine hydrochloride, uric acid, and urease assay kit were purchased from Sigma-Aldrich. Sodium chloride, potassium chloride, sodium dihydrogen phosphate monohydrate, potassium dihydrogen phosphate, disodium hydrogen phosphate heptahydrate, ethanol, chloroform and acetonitrile were provided by Scharlau. Oligonucleotide (Alexa Fluor 647)-5'-AATGCTAGCTAATCAATCGGG-3' was provided by Thermo Fisher.

General methods. Powder X-ray diffraction (PXRD), transmission electron microscopy (TEM), $\mathrm{N}_{2}$ adsorption-desorption isotherms, UVvisible and fluorescence spectrophotometries, dynamic light scattering (DLS), and elemental analysis were employed for materials characterization. PXRD measurements were performed on a Seifert 3000TT diffractometer using $\mathrm{CuK}_{\alpha}$ radiation. TEM images were acquired using a JEOL TEM-1010 Electron microscope. $\mathrm{N}_{2}$ adsorption-desorption isotherms were recorded using a Micromeritics TriStar II Plus automated analyzer. UV-visible spectra were recorded with a JASCO V-650 Spectrophotometer. Fluorescence measurements were carried out on a JASCO FP-8500 Spectrophotometer. DLS experiments were performed with a ZetaSizer Nano ZS (Malvern). Elemental analysis was performed using a CE Instrument EA-1110 CHN Elemental Analyzer.

Synthesis of mesoporous silica nanoparticles (MSNPs). First, $1.00 \mathrm{~g}$ $(2.74 \mathrm{mmol})$ of $n$-cetyltrimethylammonium bromide $(\mathrm{CTABr})$ was dissolved in $480 \mathrm{~mL}$ of deionized water. Next, $3.5 \mathrm{~mL}$ of a $2 \mathrm{~mol} \cdot \mathrm{L}^{-1}$ $\mathrm{NaOH}$ were added solution and the temperature was increased to $80^{\circ} \mathrm{C}$. Then, $5.0 \mathrm{~mL}$ of TEOS $(22.4 \mathrm{mmol})$ were added to the stirring solution. The mixture was further stirred for 2 hours at $80^{\circ} \mathrm{C}$ which yielded a white precipitate. Afterward, the solid was isolated by centrifugation, washed several times with water and dried at $70{ }^{\circ} \mathrm{C}$ overnight. Finally, $\mathrm{CTABr}$ was removed by heating the solid at $550{ }^{\circ} \mathrm{C}$ (in an oxidant atmosphere for 5 hours) which yielded the starting MSNPs.

Synthesis of gold nanoparticles (AuNPs). Gold nanoparticles were obtained by reduction of $\mathrm{Au}(\mathrm{III})$ with citrate. First, $100 \mathrm{~mL}$ of $\mathrm{HAuCl}_{4} \cdot 3 \mathrm{H}_{2} \mathrm{O}$ solution $\left(1.16 \times 10^{-2} \%\right)$ were refluxed under magnetic stirring. Then, $1.57 \mathrm{~mL}$ of $1 \%$ sodium citrate solution were added to induce the formation $20 \mathrm{~nm}$ gold nanoparticles. The initially faint yellow colour turned to blue-black and finally to red wine in a few minutes. After
10 minutes refluxing, the colloidal suspension was let to cool at room temperature. This process was repeated four times.

Synthesis of Janus Au-MSNPs. $180 \mathrm{mg}$ of MSNPs were dispersed in 9 $\mathrm{mL}$ of aqueous solution (6.7\% ethanol) and $n$-cetyltrimethylammonium bromide $(\mathrm{CTABr})$ was added for a $1 \mu \mathrm{M}$ final concentration. The mixture was heated at $75^{\circ} \mathrm{C}$, and then $1 \mathrm{~g}$ of paraffin wax was added. Once the paraffin was melted, the mixture was vigorously stirred for 15 minutes using an Ultra-Turrax T-8 homogenizer (IKA). Afterward, the mixture was further stirred for $1 \mathrm{~h}$ and $75^{\circ} \mathrm{C}$ using a magnetic stirrer. The resulting Pickering emulsion was then cooled to room temperature, mixed with 9 $\mathrm{mL}$ of methanol and reacted with $180 \mu \mathrm{L}$ of (3mercaptopropyl)trimethoxysilane for 3 hours. The solid was collected by centrifugation and washed twice with methanol. Then, the resulting MSNPs were dispersed in $68 \mathrm{~mL}$ of methanol and added over $400 \mathrm{~mL}$ of the as-synthesized AuNPs. The mixture was stirred overnight. Afterward, the solid was isolated by filtration and exhaustively washed with ethanol and with chloroform in order to remove the paraffin. The solid was dried at room temperature and ground. This process finally yielded the Janus Au-MSNPs.

Synthesis of S0. A suspension of $30 \mathrm{mg}$ of Au-MSNPs in $5 \mathrm{~mL}$ of acetonitrile was treated with $50 \mu \mathrm{L}$ of 3-mercaptopropionic acid in order to functionalize the gold face. The mixture was stirred at room temperature for 1 hour. Afterward, nanoparticles were isolated by centrifugation, washed exhaustively with acetonitrile and dried at room temperature overnight. The next day, the solid was suspended in $2.5 \mathrm{~mL}$ of acetonitrile and reacted with $60 \mu \mathrm{L}$ of (3-aminopropyl)triethoxysilane for 5.5 hours in order to functionalize the mesoporous face with amino groups. The solid was isolated by centrifugation, washed once with acetonitrile and once with ethanol and was dried at room temperature. This process finally yielded the solid SO.

Preparation of S1. In order to prepare the sensing nanodevice, $1 \mathrm{mg}$ of So was dispersed in $450 \mu \mathrm{L}$ of sodium phosphate buffer $(\mathrm{pH} 7.5,50 \mathrm{mM})$ and mixed with $50 \mu \mathrm{L}$ of labelled-oligonucleotide solution $(100 \mu \mathrm{M})$. The solution was placed in a shaker at $37^{\circ} \mathrm{C}$ for 30 minutes. Afterward, the excess of oligonucleotide was removed by centrifugation and the solid was mixed with $0.5 \mathrm{mg}$ of urease, $0.35 \mathrm{mg}$ of EDC and $0.35 \mathrm{mg}$ of NHS in sodium phosphate buffer $(500 \mu \mathrm{L}, \mathrm{pH} 7.5,50 \mathrm{mM})$. The sample was placed in a shaker a $4{ }^{\circ} \mathrm{C}$ overnight. Finally, the nanoparticles were isolated by centrifugation, washed several times with buffer and kept in the refrigerator until use.

Enzymatic assay. Urease activtiy of $\mathbf{S 1}$ was evaluated using a commercial kit provided by Sigma-Aldrich. It is based on measuring the ammonia produced by the enzymatic reaction using the Berthelot's reagent (an alkaline solution of phenol and hypochlorite) which results in the formation of the colored indophenol blue. ${ }^{[21]}$ First, samples are incubated 10 minutes with a urea solution, followed by stopping the reaction and further incubation for 30 minutes with the Berthelot's reagent. Following the technical procedure, the absorbance at $670 \mathrm{~nm}$ for the ammonium standards was measured to obtain the calibration curve showed in Figure SI-6. From the absorbance of indophenol blue obtained by incubation with $\mathbf{S} 1\left(0.01 \mathrm{mg} \cdot \mathrm{mL}^{-1}\right)$ or with commercial enzyme $\left(0.2 \mu \mathrm{g} \cdot \mathrm{mL}^{-1}\right)$, we calculated their urease activity by applying the formula:

$$
\text { Urease activity }\left(\frac{\text { units }}{g}\right)=\frac{\left(A_{670}\right)_{\text {sample }}-\left(A_{670}\right)_{\text {blank }}}{\text { Slope } \cdot t \cdot C}
$$

Where:

$\mathrm{t}=$ incubation time of with urea $(10 \mathrm{~min})$ 
$\left(A_{670}\right)_{\text {sample }}=$ Absorbance value for sample

$\left(A_{670}\right)_{\text {blank }}=$ Absorbance value for assay blank (0.06)

Slope $=$ slope of the calibration line in Figure SI-6 $\left(0.0015 \mu \mathrm{M}^{-1}\right)$

$\mathrm{C}=$ concentration of the sample.

The determined urease activity for $\mathbf{S 1}$ was $830 \mathrm{U} \cdot \mathrm{g}^{-1}$ and for the commercial enzyme was $65333 \mathrm{U} \cdot \mathrm{g}^{-1}$, from which an equivalent amount of $12.7 \mathrm{mg}$ of enzyme per $\mathrm{g}$ of $\mathbf{S} \mathbf{1}$, was calculated.

Sensing experiments. In a typical experiment, refrigerated solutions of S1 were brought to a concentration of $0.3 \mathrm{mg} \cdot \mathrm{mL}^{-1}$ in aqueous solution (PBS, pH 7.5) containing the corresponding amount urea and were stirred at room temperature $\left(25^{\circ} \mathrm{C}\right)$ in a thermoshaker. Aliquots were taken at scheduled times, centrifuged $(2 \mathrm{~min})$ to remove the nanoparticles and then the emission of fluorescent-DNA at $664 \mathrm{~nm}$ was measured $\left(\lambda_{\mathrm{exc}}=649 \mathrm{~nm}\right)$. On the other hand, human blood samples were obtained from a healthy volunteer thanks to the support of our university health centre. Red blood cells were separated from serum by centrifugation (10 $\mathrm{min}$ at $11000 \mathrm{rpm}$ ) and serum samples were further centrifuged (5 min, $11000 \mathrm{rpm}$ ) using Amicon Ultra-05 centrifugal filters units with Ultracel-10 membranes to remove proteins (see Figure SI-7). For analysis, $15 \mu \mathrm{L}$ of serum spiked with the corresponding amount of urea were added over $135 \mu \mathrm{L}$ of $\mathbf{S 1}$ aqueous solution $\left(0.3 \mathrm{mg} \cdot \mathrm{mL}^{-1}\right)$. After 10 minutes of incubation, samples were centrifuged to remove the nanoparticles and the emission at $664 \mathrm{~nm}\left(\lambda_{\mathrm{exc}}=649 \mathrm{~nm}\right)$ was measured. Milk samples were also centrifuged (5 min, $11000 \mathrm{rpm}$ ) with Amicon Ultra-05 centrifugal filters units with Ultracel-10 membranes to remove turbidity and then $15 \mu \mathrm{L}$ of sample were added over $135 \mu \mathrm{L}$ of $\mathbf{S 1}$ aqueous solution and incubated for 10 minutes before measuring the emission spectra.

\section{Acknowledgements}

A. Llopis-Lorente is grateful to "La Caixa" Banking Foundation for his PhD fellowship. The authors thank to the Spanish Government (MINECO Projects MAT2015-64139-C4-1, AGL2015-70235-C2-2-R, CTQ2014-58989-P and CTQ201571936-REDT) and the Generalitat Valencia (Project PROMETEOII/2014/047) for support. The Comunidad de Madrid (S2013/MIT-3029, Programme NANOAVANSENS) is also gratefully acknowledged.

Keywords: nanosensors $\bullet$ biosensors $\bullet$ chromo-fluorogenic probes $\cdot$ urea sensing $\bullet$ nanotechnology

[1] a) T. D. Ashton, K. A. Jolliffe, F. M. Pfeffer, Chem. Soc. Rev. 2015, 44 4547-4595; b) X. Zhou, S. Lee, Z. Xu, J. Yoon, Chem. Rev. 2015, 115 7944-8000; c) L. E. Santos-Figueroa, M. E. Moragues, E. Climent, A. Agostini, R. Martínez-Máñez, F. Sancenón, Chem. Soc. Rev. 2013, 42 3489-3613; d) M. H. Lee, J. S. Kim, J. L. Sessler, Chem Soc. Rev. 2015, 44, 4185-4191

[2] a) W. Sun, S. Guo, C. Hu, J. Fan, X. Peng; Chem. Rev. 2016, 116, 7768-7817; b) E. Garrido, L. Pla, B. Lozano-Torres, S. El Sayed, R. Martínez-Máñez, F. Sancenón, ChemistryOpen 2018, 7, 401-428.

[3] a) D. Wu, A. C. Sedgwick, T. Gunnlaugsson, E. U. Akkaya, J. Yoon, T. D. James, Chem Soc. Rev. 2017, 46, 7105-7123; b) R. MartínezMáñez, F. Sancenón, Chem. Rev. 2003, 103, 4419-4476; c) J. Wu, B.
Kwon, W. Liu, E. V. Anslyn, P. Wang, J. Seung-Kim. Chem. Rev. 2015 115, 7893-7943; d) Y. Ding, W.-H. Zhu, Y. Xie, Chem. Rev. 2017, 117, 2203-2256.

[4] a) E. Persch, O. Dumele, F. Diederich, Angew. Chem. Int. Ed. 2015, 54, 3290-3327; b) D. Bray, Nature 1995, 376, 307-312.

[5] a) K. Ariga, D. T. Leong, T. Mori, Adv. Funct. Mater. 2018, 28 , 1702905; b) M. Komiyama, K. Yoshimoto, M. Sisido, K. Ariga, Bull. Chem. Soc. Jpn. 2017, 90, 967-1004.

[6] Y. Yi, L. Sanchez, Y. Gao, Y. Yu, Analyst 2016, 141, 3526-3539.

[7] a) A. Walther, A. H. Müller, Chem. Rev. 2013, 113, 5194-5261; b) A. Walther, A. H. Müller, Soft Matter 2008, 4, 663-668.

[8] a) Y. Song, S. Chen, Chem. Asian J. 2014, 9, 418-430; b) A. Sánchez, P. Díez, P. Martínez-Ruiz, R. Villalonga, J. M Pingarrón, Electrochem. Commun. 2013, 30, 51-54; c) C. Lu, X. Liu, Y. Li, F. Yu, L. Tang, Y. Hu Y. Ying, ACS Appl. Mater. Interfaces 2015, 7, 15395-15402; d) A. Burns, H. Owiesner, Chem. Soc. Rev. 2006, 35, 1028-1042; e) K. Aslan, M. Wu, J. Lakowicz, C. D. Geddes, J. Am. Che. Soc. 2007, 129,15241525; S. A. Kalene, S.S. Ashaputre, N. Y. Hebalkar, S. W. Gosavi, D. N. Deobagkar, D. D. Deobagkar, S. K. Kulkarni, Chem. Phys. Lett. 2005, 404, 136-141; f) Z. Wang, X. Yang, J. Feng, Y. Tang, Y. Jiang, N. He, Analyst 2014, 139, 6088-6091.

[9] G. Dhawan, G. Sumana, B.D. Malthotra, Biochem. Eng. J. 2009, 44, 42-52.

[10] a) T. W. Meyer, T. H. Hoestetter, N. Engl. J. Med. 2007, 13, 1315-1325 b) A. J. Taylor, P. Vadgama, Ann. Clin. Biochem. 1992, 29, 245-264; c) M. Singh, N. Verma, A. K. Garg, N. Redhu, Sens. Actuators B Chem. 2008, 134, 345-351.

[11] a) J. Qin, K. Chao, M. S. Kim, Food Chemistry 2013, 138, 998-1007; b) C. F. Nascimiento, P. M. Santos, E. Rodrigues Pereira-Filho, F. R. P Rocha, Food Chemistry 2017, 221, 1232-1244.

[12] a) U. B. Trivedia, D. Lakshminarayana, I. L. Kothari, N. G. Patel, H. N Kapse, K. K. Makhija, P. B. Patel, C. J. Panchal, Sens. Actuators B Chem. 2009, 1, 140-266; b) W. Butler, J. Calaman, S. Beam, J. Anim. Sci. 1996, 74, 858-865.

[13] a) V. Kumar, R. Mahajan, I. Kaur, K.-Y. Kim, ACS Appl. Mater Interfaces 2017, 9, 16813-16823; b) N. S. Nguyen, G. Das, H. H. Yoon, Biosens. Bioelectron. 2016, 77, 372-377; c) Z. Yang, X. Liu, C. Zhang, B. Liu, Biosens. Bioelectron. 2015, 74, 85-90; d) S. Jakhar, C. S. Pundir, Biosens. Bioelectron. 2018, 100, 242-250; e) E. Dervisevic, M. Dervisevic, J. K. Nyangwebah, M. Senel, Sens. Actuators B Chem. 2017, 246, 920-926; f) M. Dervisevic, E. Dervisevic, M. Senel, Sens. Actuators B Chem. 2018, 254, 93-101; g) T. Alizadeh, M. R. Ganjali, F. Rafiei, Anal. Chim. Acta 2017, 974, 54-62; h) R. Sha, K. Komori, S. Badhulika, Electrochim. Acta 2017, 233, 44-51; i) V. Kumar, A. Chopra, S. Arora, S. Yadav, S. Kumar, I. Kaur, RSC Adv. 2015, 5, 13278 13284 ; j) S. V. Marchenko, I. S. Kucherenko, A. N. Hereshko, I. V Pansiuk, O. O. Soldatkin, A. V. El'skaya, A. P. Soldatkin, Sens Actuators B Chem. 2015, 207, 981-986; k) P. Kumar, P. R. Lambadi, N K. Navani, Biosens. Bioelectron. 2015, 72, 340-347; I) A. W. Zaibudeen, J. Philip, Sens. Actuators B Chem. 2018, 255, 720-728.

[14] R. K. Srivastava, S. Srivastava, T. N. Narayanan, B. D. Mahlotra, R. Vajtai, P. M. Ajayan, A. Srivastava, ACS Nano 2012, 1, 168-175.

[15] a) E. Climent, R. Martínez-Máñez, F. Sancenón, M. D. Marcos, J. Soto A. Maquieira, P. Amorós, Angew. Chem. 2010, 122, 7439-7441; b) M. Oroval, C. Coll, A. Bernardos, M. D. Marcos, R. Martínez-Máñez, D. G. Shchukin, F. Sancenón, ACS Appl. Mater. Interfaces 2017, 9, 11332 11336; c) M. Oroval, E. Climent, C. Coll, R. Eritja, A. Aviñó, M. D. Marcos, F. Sancenón, R. Martínez-Mañez, P. Amorós. Chem. Commun. 2013, 49, 5480-5482.

[16] A. Llopis-Lorente, P. Díez, A. Sánchez, M. D. Marcos, F. Sancenón, P. Martínez-Ruíz, R. Villalonga, R. Martínez-Mañez, Nat. Commun. 2017 8, 15511.

[17] A. L. Doadrio, J. M. Sánchez-Montero, J. C. Doadrio, A. J. Salinas, M. Vallet-Regí, Micropor. Mesopor. Mater. 2014, 195, 43-49. 
[18] V. Balladur, A. Theretz, B. Mandrand, J. Colloid Interface Sci. 1997, 194, 408-418.

[19] L. Liu, H. Mo, S. Wei, D. Raftery, Analyst 2012, 137, 595-600.

[20] P. S. Francis, S. W. Lewis, K. F. Lim, Trends Analyt. Chem. 2002, 21, 389-400.
[21] Y. Moliner-Martínez, R. Herráez-Hernández, P. Campíns-Falcó, Anal. Chim. Acta 2005, 534, 327-334. 


\section{FULL PAPER}

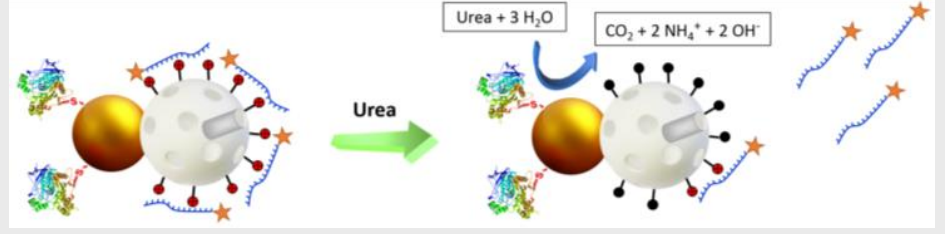

We present a novel paradigm for the design of optical sensors based on nanodevices incorporating an enzymatic receptor subunit and a hybrid signalling subunit that communicate through chemical messengers. As a proof of concept, a urea nanosensor based on the release of Alexa Fluor 647-labelled oligonucleotide from urease-functionalized Janus Au-MSNPs (gold-mesoporous silica nanoparticles) has been developed.
Antoni Llopis-Lorente, Reynaldo Villalonga, * María Dolores Marcos, Ramón Martínez-Máñez* and Félix Sancenón

Page No. - Page No.

Versatile new paradigm for the design of optical nanosensors based on enzyme-mediated detachment of labelled-reporters: The example of urea detection 